\title{
THE HESLOP ENGINE, \\ A CHAPTER IN THE HISTORY OF THE STEAM ENGINE.
}

By Mr. H. A. FLETCHeR, of Whitehavex.

So far as the writer is aware, no work upon the Steam Engine, or illustrative of its progress and gradual development, contains any mention whatever of the remarkable and ingenious engine invented by Adam Heslop and patented on 17th July 1790; and yet he conceives that it forms an important chapter in the history of the steam engine, as a somewhat successful competitor with the improved engine of James Watt, and as containing within it the germ of the compound engine of the present day. Probably it was never much known beyond the somewhat limited coalfield of Cumberland, where for many years it enjoyed great favour; and even within that district it is at the present time gradually becoming forgotten, and its principles and merits are understood by only a few. Only one specimen now (March 1878) remains, which has ontlived by many years all other members of its family; and as this also, after a faithful service of more than fourscore years, will cease from its labours in a few months-when it will probably find at the Patent Office Museum an honourable place of retirement in the company of the Soho sun-and-planet engine, and the locomotives Rocket, Sanspareil, and Puffing Billy-the present seems a fitting opportunity to place on record some account of the Heslop Engine.

The accompanying drawings, Figs. 1 and 2, Plate 7, are copied from the engraving attached to the original specification, beneath which is the following explanation:- "A Receiving Cylender A is placed under the beam of the Engine B, between the center of the Beam and the end opposite to that which is moved by and connected with the working Cylender $\mathbf{C}$ used in the Common Fire Engine. 
The aforesaid Receiving Cylender is filled with Steam from the Boiler $\mathrm{D}$, sufficient to produce a vacuum in the working Cylender for the next stroke of the Engine, and which Steam so received in reserve is made to assist in raising a piston $\mathbf{E}$, which must be loaded with so much weight upon every square inch as the Steam shall be stronger than the pressure of the Atmosphere, and which will consequently assist the Engine in its effeet by giving an opportunity of loading the working piston $F$ with the same weight. Near to the middle of the said working piston $F$ is placed a Valve $L$, which admits the discharge of a small portion of Water which arises on the descending stroke of the said Piston F, and supplies the same with Water. The Steam Valvo marked $G$, which opens the communication between the Boiler and the Receiving Cylender, is similar to that in the Common Engine, and worked in the samo way. The passage for the Steam from the Receiving Cylender to the working Cylender is by a connecting pipe $\mathrm{H}$, which is opened and shut alternately by Valves marked $I$ and $K$, and the motion is communicated to those Valves by working gears nearly similar to that of the Common Engine. The working Cylender C, together with the connecting pipe $\mathrm{H}$, to be constantly immersed in cold water. The Injection and sinking pipes of the working Cylender are all similar to those in common use."

This explanation is not very explanatory, and is worded with evident caution; for it was probably as necessary and desirable ninety years ago as it is now to say but little in a patent specification, and to say that little cautiously. With the aid of the drawing however the action of the engine will be readily understood. It will be seen that it is furnished with two opentopped cylinders, one on each side of the main centre of the beam, and both of them single-acting, although their pistons are acting in the same direction. These cylinders are described respectively as the "receiving cylinder" and the "working cylinder," the latter" being possibly so called lest Boulton and Watt should contend it was only a condenser with a piston in it; but in actual practice they were known, and perhaps more correctly, as the hot cylinder and the cold cylinder. The steam on being admitted into the first or hot. 
cylinder helps to raise the piston by its pressure underneath; the return stroke is then made by the weight of the pump rods \&c. in the pit, suspended by a chain working over an arched beam-head. During the downstroke of the pump rods, the eduction valve $I$ being opened, the steam passes from this cylinder to the second or cold cylinder by means of the connecting pipe constantly immersed in a trough of cold water, which produces sufficient condensation to "kill" or reduce it to atmospheric pressure as it enters and fills the cold cylinder. The cold piston having arrived at the top of its stroke, and its cylinder being thus filled with steam, the injection valve is opened, admitting a jet of water beneath the piston, and thus bringing a vacuum into play. In the case of ratative engines the return stroke was made by the weight of the connecting-rod, crank, and a heary pair of links attaching the hot piston to the beam, assisted by the momentum of the flywheel. Weighting the pistons in order to profit by the pressure of steam is necessitated by the arched head and chain connection, which, though proper to receive a pull, will not admit of a thrust. In order to prevent the possibility of injection-water passing from the cold cylinder to the hot one, the latter is elevated above the level of the former.

By this arrangement of two cylinders Heslop obtained advantages closely approaching those of the separate condenser, and effected a signal superiority over the atmospheric engine of Newcomen, even as it then existed with all the structural improvements introduced by Smeaton; who was compelled to admit that, in its best state, 50 per cent. of the steam was wasted by the alternate heating and cooling of the cylinder.

Mr. Heslop does not appear to have been guided by any fixed rule in the relative proportionate capacity of the two cylinders. In the specification drawing they appear to be practically equal in content, whilst in five instances in which the dimensions have been ascertained the hot cylinder is invariably the larger, being respectively $8,53,75,78$, and 87 per cent. larger in capacity than the cold one. Doubtless he found sufficient reasons for gradually decreasing the proportions of the cold cylinder; but with higher pressures of steam 
than were then in use there seems no cause why these proportions might not be reversed.

The following engines on the Heslop principle, fifteen in number, may be mentioned as thoroughly authenticated; there were probably some others, of which all trace or record is lost. The enumeration here given has regard to locality rather than to probable chronological order.

No. 1.-A pumping engine, known by the name of "Old Dolly," at Messrs. Harris's Greysouthen Colliery. The beam was of wood, with arch-heads and chains, and the pistons were weighted with pig iron; in fact, even to the boiler and chimney, it was almost exactly similar to the engine shown in the specification drawing, except that the main centre of the beam was not carried by a wall, but by a wooden $A$ frame, the sides of which, being boarded all round, formed a sort of pyramidal hut over the hand gear. This is believed to have been the earliest engine of its kind; it retained nearly all its original features and detrils until the last, and was broken up about thirty years ago. Its boiler, like those of all the Heslop engines, was of the haystack form. The hemispherical tops were of cast-iron plates, not fitted, and fastened together by means of bolts and rust joints; whilst the lower portions were of wrought iron. The maximum working pressure was usually about $3 \mathrm{lb}$. per square inch above the atmosphere.

No. 2.-A pumping engine erected at Mr. Joseph Stead's Bolton Colliery near Wigton; of which no particulars have been obtained.

No. 3.-A winding engine at Risehow Pit near Maryport, afterwards removed to Greengill Colliery.

No. 4.-An engine at Church Pit, Workington, which was employed both for pumping and for winding, but not simultaneously. The hot cylinder was $25 \frac{3}{4}$ inches diameter with a stroke of $2 \mathrm{ft} .6 \frac{1}{2}$ in., and the cold cylinder 22 inches diameter with a stroke of $3 \mathrm{ft} .2 \mathrm{in}$.

No. 5.-A winding engine at Isabella Pit, Workington, with a cast-iron beam; hot cylinder 36 inches diameter with $2 \mathrm{ft} .6$ in. stroke; cold cylinder $22 \frac{1}{4}$ inches diameter with $3 \mathrm{ft}$. 6 in. stroke. 
It was afterwards removed to Jane Pit, and converted into an ordinary high-pressure engine.

No. 6.-A winding engine with cast-iron beam at John Pit, Harrington; it was built in 1810, and was called 16 horse-power, and wound coals from 95 fathoms depth, with the assistance of a balance sheave. It was altered into a high-pressure engine by Daniel Hawthorn, a brother of Robert and William Hawthorn, of Newcastle fame, and for some time manager at Lowca Works under Messrs. Tulk and Ley. The Heslop engine seems to have been a puzzle to Mr. Hawthorn, who confessed that he never could thoroughly comprehend its working, adding however the consolatory reflection that he was quite sure nobody else did.

No. 7.-A winding engine at Henry Pit, also one of the Harrington Collieries, of 12 horse-power and with a wooden beam.

No. 8.-An 8 horse-power engine, probably for winding, with a wooden beam, at Hodgson Pit, Harrington. This was afterwards removed to make way for a larger and superior winding engine, No. 9, removed there from Micklam. The latter may be regarded as exhibiting Mr. Heslop's best work and later improvements. The beam was supported by a cast-iron framing, whilst the whole engine stood on cast-iron girders, requiring only two or three cross-walls for the support of the whole. The beam was a single casting of peculiar form, convex on the lower side but flat on the upper, the main centre being in the same line with the upper edge, but fortified by a semi-circular piece over it. This engine stood exposed to the weather for some time after its abandonment, and was broken up about fourteen years ago.

No. 10.-An engine with cast-iron beam, erected by Messrs. Heslop about 1799 or 1800 for driving their own works at Lowca.

No. 11.-An engine with wooden beam at Mr. Walker's Gilgarron Colliery.

No. 12.-A 10 horse-power winding engine, first erected at Boon Wood and afterwards at Dion, both near Distington. This was constructed in 1829, and was the last ever made on the Heslop system; it was contracted for at the price of $£ 600$, or at the rate of 
$£ 60$ per nominal [horse-power, with all the winding gear charged extra ad libitum.

No. 13.-A large winding engine at William Pit, Whitehaven Colliery, erected in 1809, and shown in Fig. 3, Plate 8, which is copied from a drawing in the possession of the Earl of Lonsdale. The beam, B, was a combination of wood and iron, consisting of two open-sand castings, somewhat in the form of the principals of a king-post roof, bolted together, with a $\log$ of wood between them. The throw of the crank was $5 \mathrm{ft} .6$ in., the hot cylinder, A, 44 inches diameter with a stroke of $3 \mathrm{ft} .6$ or $3 \mathrm{ft} .7 \mathrm{in}$., and the cold cylinder, $\mathrm{C}$, 28 inches diameter with $4 \mathrm{ft} .9 \mathrm{in}$. stroke. The piston-rod of the cold cylinder was connected to the beam by means of a parallel motion; and that of the hot cylinder by links, with guides for the crosshead. The engine was furnished with an air-pump 14 inches. diameter; and the flywheel was $20 \mathrm{ft}$. diameter. For forty years this engine drew a large quantity of coal daily from a depth of 106 fathoms, with considerable economy of fuel, and with a remarkably small expenditure in repairs. It was broken up in 1850 .

No. 14.-A winding engine at Lady Pit (afterwards removed to Wilson Pit), of which also a drawing is extant at the Whitehaven Colliery office. Judging by the scale the hot and cold cylinders appear to have been respectively 30 and 20 inches diameter, with strokes of $2 \mathrm{ft} .8 \mathrm{in}$. and $3 \mathrm{ft}$. The date of this engine is supposed to be 1795 , and it was without any air-pump, like all made previous to the year 1800, in which Watt's first patent terminated, after having been prolonged by Act of Parliament in 1775 for the additional period of twenty-five years. The piston-rod of the cold cylinder was attached to the wooden beam by means of a chain passing over an arch-head, whilst that of the hot cylinder was connected by cast-iron links. The boiler was fed, as was then usual, by a jack-head pump, the delivery box of which does not appear to have been more than 7 feet above the water-level; consequently the boiler pressure could never exceed a maximum of a little over 3 lbs. per square inch. This pump, being connected with the discharge pipe from the cold cylinder, must to some extent have served also as an air-pump. Other earlier engines had a similar arrangement. 
No. 15.-The last of these engines which remains to be noticed is the one first alluded to as the only existing representative of its kind. It was probably made about 1795 , or a few jears earlier or later, and was originally at Kell's Pit, then at Castlerigg, and in 1837 was removed to its present position at Wreah Pit, all owned by the Earls of Lonsdale and forming part of their Whitehaven Colliery.

The accompanying drawings, Figs. 4 and 5, Plate 9, are made from actual dimensions taken recently. The hot cylinder, A, is 34 inches diameter with $2 \mathrm{ft} .10 \mathrm{in}$. stroke, and the cold cylinder, C, $25 \frac{1}{2}$ inches diameter with $3 \mathrm{ft} .3 \mathrm{in}$. stroke. The wooden beam, B, has been frequently renewed, and a symptom of fracture in the present one is met by two pieces of old boiler-plate patched over the middle portion; the present hog-backed shape is modern, the original beam having been parallel in form. The air-pump of 12 inches diameter has been an after-addition; and the snifting valve in the cold piston is plugged up, being apparently no longer necessary. A drawing made about the year 1823 shows an air-pump placed outside the cold cylinder, and worked through a double-radins parallel-motion, by means of a small beam attached to the end of the main beam by a long connecting-link. Nevertheless the cold piston still did its work through a chain and arch-head, and it was probably not till 1837 that the now existing links and crosshead guides were substituted. The original cast-iron flywheel shaft has been replaced by a wrought-iron one of the same dimensions. The winding gear is on a second-motion shaft, which is not parallel to the first, and is driven from it by a bevel pinion, $D$, on the flywheel shaft, working into an ordinary spur wheel with parallel teeth upon the winding shaft. The curiously bent connecting-rod, E, was a common feature in all Heslop's rotative engines; and though its obvious intention is to clear the hot cylinder, he contended that it gave a certain amount of elasticity which was beneficial and desirable. The cold-water pump discharges itself upon the top of the cold piston, from which it overflows on the upstroke into the cistern in which the cylinder is placed. This engine also pumps, by means of a cast-iron beam added about forty years ago, and placed some 4 or 5 feet above the level of the main beam, to which it is connected by links. 
An attempt has been made to indicate this engine; but from its ricketty condition, bad joints, and rather insufficient supply of cold injection water at the time, the result was not entirely satisfactory, yet sufficient to prove the mode of operation of the steam. With about $20 \mathrm{lb}$. per sq. in. pressure in the boiler, which is not the original haystack but an ordinary egg-ended boiler, the maximum pressure in the hot cylinder was $16 \frac{1}{2} \mathrm{lb}$. In the case of the cold cylinder it was needful to attach the indicator to a tube inserted in the top of the piston, the presence of injection water in the cylinder making it impossible to apply it in the usual way. In the upstroke of this piston the diagram showed the pressure reduced to the atmospheric line, which it follows till towards the end of the stroke, when there is a slight fall below that line, arising it is believed from some of the cold water that is constantly poured over the top, passing the badly packed piston into the interior of the cylinder. The diagrams were taken whilst the engine was pumping.

Adam Heslop was the son of a blacksmith, settled at Workington, and said to be a Scotchman. Along with his two brothers Crosby and Thomas, Adam also followed the same craft, which then included what little was known or requisite in the fitting of machinery and the use of the lathe; and all the three were employed as smiths at the Seaton Iron Works near that town, then and sometimes now better known as the Barepots or Beer-pot Works. Thomas seems to have been an adept in the art of boring cannon for the armament of merchant ships, a considerable article of manufacture in the days when every foreign-going vessel carried a number of guns. In very early life Adam Heslop went to Coalbrookdale and the neighbouring iron district, for the purpose of improvement and experience; and it was whilst residing at Ketley, near Wellington in Shropshire, that he patented his engine in the year 1790. Probably he returned to Seaton Works not long afterwards; and it is conjectured that two or three of the earliest of the engines which bore his name were constructed there. But in 1798 or 1799 he founded the Lowea Iron Works near Whitehaven, in conjunction with his two brothers, Mr. William Stead of Bolton (Cumberland), Mr. Johnson a merchant of 
Whitehaven, a lady named Ritson, and Mr. Millward (who ultimately became proprietor of the whole), under the style or firm of Heslops, Johnson, Millward and Company. Adam held three-sixteenths, Crosby two, and Thomas one; but Thomas retired in 1803 in order to join a Mr. Mead in the business of an iron merchant and anchorsmith, receiving for his interest in the concern the modest sum of £186 188.

William Stead was a younger brother of the John Stead or Steed (Stead is prononnced Steed in the vernacular of Cumberland), who, whilst occupied at Birmingham in the year 1781, patented the application of the crank to the steam engine. Watt states, in the well-known letter on the subject to his son, which is published in Muirhead's "Mechanical Inventions of James Watt," that he himself was then experimenting with the crank, but that whilst he was considering about it Stead took out his patent; and he accuses one of his own workmen of treachery in the matter, but at the same time admits that Stead might have invented it independently, as no doubt he did, having, according to the statement of his grandson, $\mathrm{Mr}$. Charles Wilson, now of Shotley Park, taken the idea from his wife's spinning-wheel. It is a curious fact however that no trace of Stead's patent is to be found, although a patient and careful search was made for it at the patent office by $\mathbf{M r}$. Bennet Wooderoft; possibly some cause or other may have prevented the deposit of the complete specifioation within the time prescribed by law.

Mr. Fletcher said that since the paper had been written (now the greater part of a year ago) the old engine at Wreah Pit, shown in Plate 9, which stopped working last June, had been carefully removed to South Kensington, and was there being erected in the Patent Office Museum; its erection would probably be completed in the course of a fortnight. In making that announcement he desired 
to acknowledge the very ready way in which Lord Lonsdale, the owner of the engine, had consented to present it to the museum; and also the equally ready manner in which Colonel Stuart Wortley, the curator of the museum, had made room for it under circumstances of considerable difficulty, the museum being already very much too crowded. He might also mention that the London and North Western Railway had liberally conveyed the engine at a very reduced rate.

It would be observed that the specification drawing showed a check valve at $K$, in the eduction pipe passing from the first cylinder to the second; but he could not find that in practice this valve had ever been used. It did not exist in the surviving engine, nor was it shown in any of the extant early drawings of other examples of the Heslop engine.

The President enquired what was the object, if any, of having both pistons loaded with the same amount of weight, one on one side of the beam centre and the other on the other, as deseribed in the original specification of the engine; the result being apparently to neutralise each other's action. He might have misapprehended the construction; or perhaps, like Mr. Daniel Hawthorn, he could not understand it after hearing it described. It did not appear to him that there was any advantage in loading both pistons with the samo weight.

Mr. A. Paget said, if he understood the description rightly, the weight loading the piston was only employed in the engine having chain connections to the beam; and if so, of course it would be to keep the chains taut. The specification drawing showed the chain connection at both ends of the beam, which would require both pistons to be weighted.

Mr. FletCher said it should be borne in mind that at that time there was no known mode of connecting pistons with a beam, except by means of chains and arched heads, without infringing upon Watt's parallel motion; and it would be seen that in the first or hot 
cylinder, Mr. Heslop desired to avail himself of steam pressure in order to drive the piston up; the chain connection would not communicate to the beam the upward thrust produced by that pressure, and therefore he balanced both pistons with pig iron, so that the action of the steam was simply to support the weight on the piston of the first or receiving cylinder, and then the weight on the piston of the second or working cylinder pulled up the chain. When afterwards Mr. Heslop attached a crosshead and guides to the hot-cylinder piston-rod, with the heavy cast-iron links to attach it to the beam, as mentioned in the paper, this weighting of the pistons was of course no longer required.

All the Heslop engines that had been traced were colliery engines used for pumping or winding, with the one exception of the engine that had been put up for driving the machinery at the Lowca Works, Whitehaven, where it had continued to work for upwards of forty years. At the end of that time, one or both of the,cylinders having become worn out, it was converted into an ordinary doubleacting condensing engine. It was not perhaps one of the best construction, and he did not suppose that there was much, if any, attempt at expansion of steam; but it was a notable fact that, after the engine had been altered, there had not been found to be any sensible diminution in the consumption of fuel.

The President thought the interest of the paper was considerably increased by the fact which Mr. Fletcher had just reported, that the original engine had now been removed to the Patent Office Museum at South Kensington. No doubt many gentlemen in visiting the museum would take the opportunity of seeing the engine, which certainly gave evidence of great mechanical invention on the part of the constructor. They were all very much indebted to Mr. Fletcher for his interesting paper, and he proposed that the thanks of the meeting be accorded to him by acclamation.

The proposal was carried by acclamation.

The following paper was then read:- 
HESLOP ENGINE.

Plece 7.

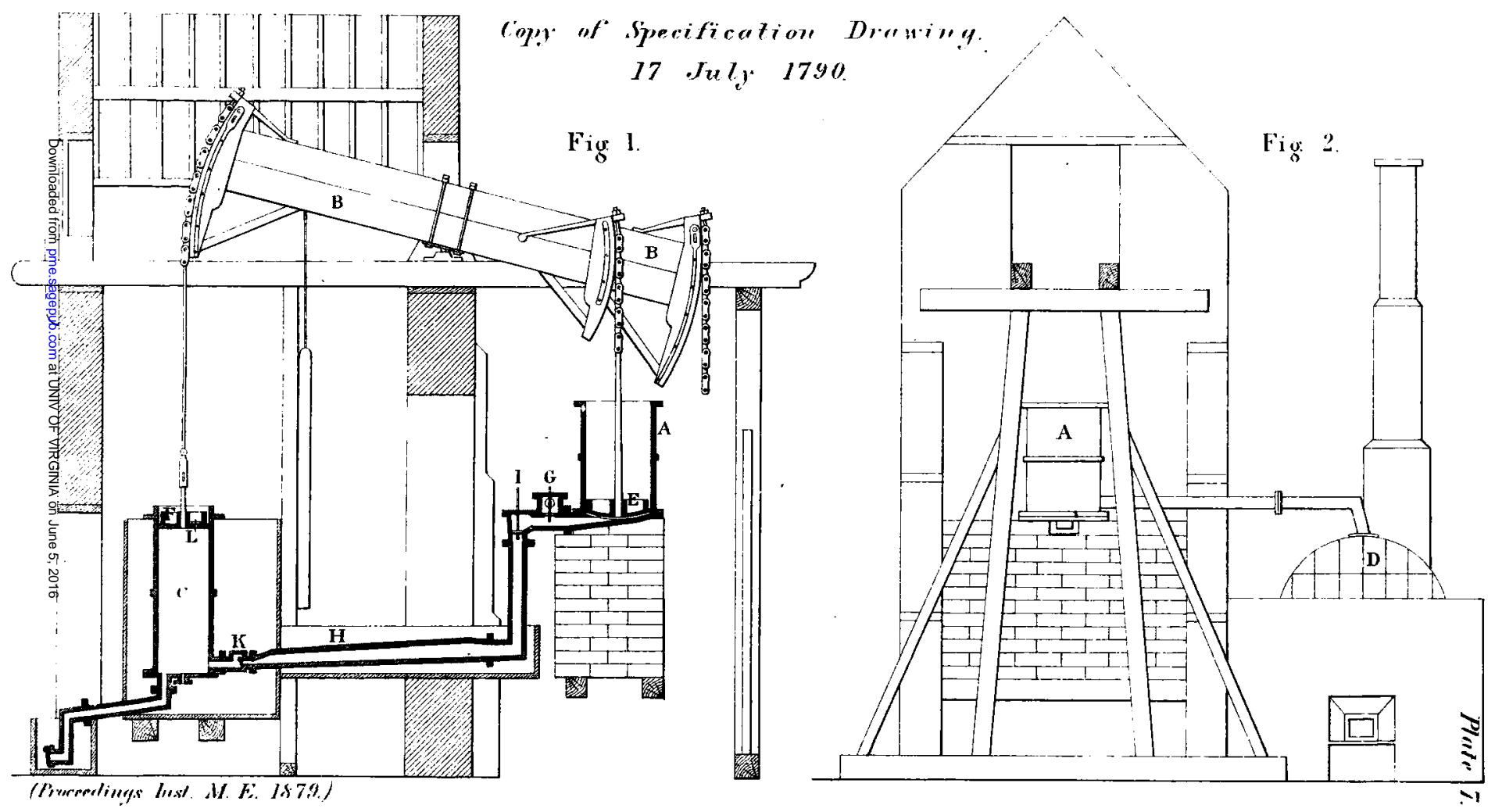




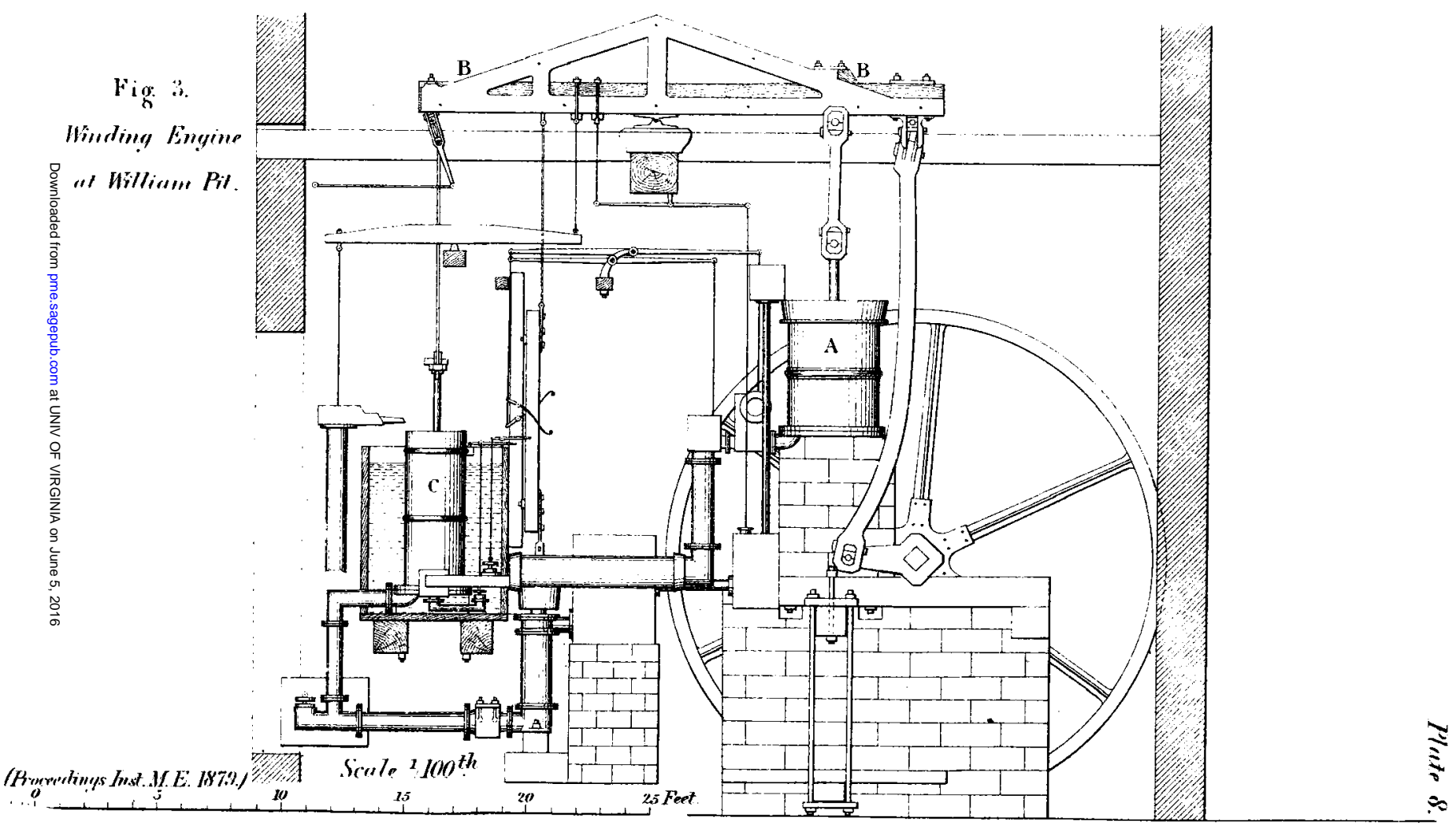


HESLOP ENGINE.

$11 / 1 / 8$

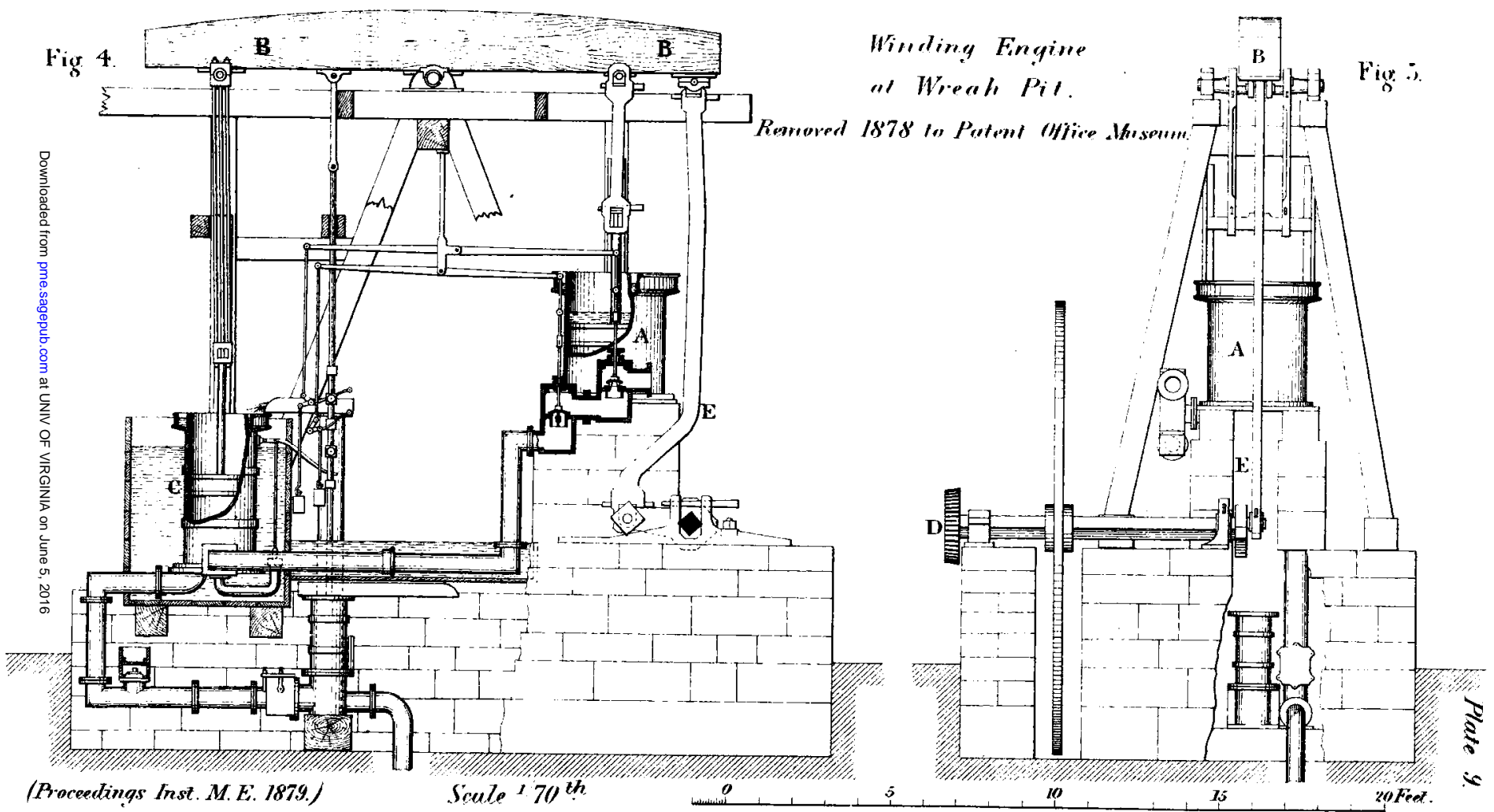

